\title{
Facilitation of Wind Energy Conversion System Selection as Distributed Generation in Household/Commercial and Agricultural Sectors; Case Study of Iran
}

\author{
Arash Hatami", Hamed Shakouri Ganjavi \\ Department of Industrial Engineering, University College of Engineering, University of Tehran, Tehran, Iran \\ *Corresponding Author: ahatami@ut.ac.ir
}

Copyright (C) 2013 Horizon Research Publishing All rights reserved.

\begin{abstract}
Distributed generation is an approach to power generation by low capacity systems. In this paper small wind turbines are investigated as distributed generation systems used to satisfy household/commercial and agricultural sectors demand. This paper explains a decision-making process during which consumers can easily define appropriate Wind Energy Conversion System (WECS), considering economical accordance by the amount of power consumption and climate condition of installation place. Rotor diameter and turbine hub height are distinguished as two main parameters affecting WECS, referring to consumption rate and climate circumstances of the place. Mathematical relation between Cost Per Unit (CPU) of generated power and these two, is determined with high correlation coefficient which will be applied during the process to easily nominate different WECSs. Having the amount of costs paid by a family per $1 \mathrm{kWh}$ of electricity consumption, WECS characteristics can be conveniently specified using this relation. To examine the influence of each of the above parameters and increasing the validity of the results, turbines with different rated powers and hub heights, are used in four regions with various geographical circumstances.
\end{abstract}

Keywords Distributed Generation, Small Wind Turbines, Wind Energy Conversion System

\section{Introduction}

Manufacturing products, providing services to increase human welfare and satisfying safe life, requires energy consumption. Electrical energy is actually one of the most important types of energy. During population growth and development of human societies, great generation of the electrical energy is inevitable. It is expected that the world electricity usage will reach 32,922 terawatt hours in the year 2035 (approximately two times the amount used in the year
2008) (Nasser Bagheri Moghaddam, 2011). Therefore, in order to respond to the increase in power demand, countries must develop generation methods and relevant facilities.

In some energy-related literatures, various methods for power generation are categorized into two sets based on primary energy, fossil or renewable energies, used as generation method. Exhaustibility of fossil resources and environmental pollutions has led to extension of electricity generation by renewable primary energy. In this realm, power generation using renewable energy is divided to two categories as hydro and non-hydro. This paper focuses on wind power generation as non-hydro renewable energy. As a fact, non-hydro renewable energies comprise about 5\% of global power generating capacity and supply about $3.4 \%$ of global electricity generation (Global status report, 2007).

The use of wind machines for utilization of the wind speed is not only new, but also reaches as far back as the Chinese in 2000 B.C., in irrigation water pumps and windmills for grinding grains.However, among these energy sources, wind is becoming the world's fastest growing renewable energy source due to its worldwide acceptance as a clean source of energy and having such attributes as security of supply, biodiversity concerns,potential for distributed generation, ecological awareness and other socio-economic factors (Seyit Ahmet, 2010). Besides, as wind can generate power near load centres, it eliminates the transmission loss in the lines through rural and urban areas (Murat, Gokcek, 2009, IEA (World energy outlook), 2010). According to World Wind Energy Association, the world wind power capacity reached 196,630 MW in 2011 after a nearly exponential growth for 5 years. It is expected that wind energy, will have a $4.9 \%$ share in meeting the world electricity demand until the year 2030 (Global Wind Energy Council, 2010). Furthermore, Modern wind power industry has witnessed huge progress in the past 30 years due to the R\&D efforts (GM Joselin Herbert, 2007). For instance, installed wind power capacity in China increased from $2599 \mathrm{MW}$ in 2006 to 44,733 MW in2011or in the U.S. this is from 11,575 MW in 2006 to 40,180 MW in 2010 (Gong Li, 2010). So, it is 
anticipated that the renewable share in electricity generation will reach $16 \%$ in the year 2035 from $1 \%$ in the year 2008 (IEA (World energy outlook), 2010).

To sum up, nowadays utilization of this form of energy is expanded all over the world and developing countries are carrying out major research to extend this generation method. According to World Wind Energy Association's (WWEA) report, installed capacity dispersion of the world wind turbines until the year 2009 , exhibited $25 \%$ of the total installed capacity of wind power in Asia. Among the continents, Europe has the largest share in increasing wind power capacity to $48 \%$ (World Wind Energy Association, 2010).

As researchers have attended climate changes and the resulting wind speed changes over various seasons of a year, there has been created opportunities to extend wind turbine applications and to develop various types such as vertical and horizontal axis wind turbines. On the other point of view, considering generation or consumption scale, wind turbines are categorized into two types, small and large turbines. Both are being served and operated by homeowners and small enterprises. In recent years, power generated by small scale wind turbines is increased. Therefore, sales has been grown averagely $40 \%$ per year, since the energy crisis of the 1970 s (American Wind Energy Association, 2002).

Among the literatures published in different fields relevant to wind power utilization so far, there are some discussing economic aspects of wind energy conversion system (WECS) and output cost analysis. Some others, have concentrated on efficiency of WECS assessing factors effecting on it (S Olayinka Ohunakin, 2012, Ciprian Vlad, 2010). But this paper tries to present a decision-making process so as to easily choose a WECS conforming consumer preferences. Against manufacturer brochures which present specific amounts as the WECS charactristics, this process can help consumer to define these amounts according to a three variables mathematical relation developed between cost per unit of generated power (CPU) and both parameters hub height $(\mathrm{H})$ of wind turbine and rotor diameter (D). On the other hand, as defining amount af the both parameters will be done considering consumption rate (affected by D) and climate conditions (affected by H), the defined WECS has more conformity to consumer preferences rather than the one defined by manufacturer. Since the WECS selected by consumer has accordance with the power supply needed and is self-agreeable as well, especially economically, this paper can help anyone serving wind power generation systems. In the following, first an introduction is provided for the well-known wind power literature and some transparent statistics of wind energy developments are investigated. Section 2 describes the methodology through which, general information, wind energy potential of Iran, decision-making process and Weibull parameters of wind speed for four selective locations are surveyed. Latest sub-sections are allocated to estimation of turbine power and way of CPU calculation. In section 3, derivation of mathematical equation based on impressed factors is completely defined. In order to sensitivity analysis and guarantee accuracy in calculations, various hub heights and rated power of wind turbines are used for locations having different climates. Finally, conclusion and groundwork of future research is depicted.

\section{Methodology Discription}

\section{Overview}

As mentioned, this paper investigates wind power generation using small wind turbines considering existing wind potential in Iran. On the other hand, considering the aspect of wind turbine utilization for satisfying electrical energy demand in household/commercial and agricultural sectors, this paper has special attention to distributed generation realm and present techno-economic analysis as an experimental practice to present a process in order to ease small wind turbines utilization.

As a general rule, wind turbines served to generate electricity are divided into three categories (i.e. small, medium, and large sized) based on the power generation. Small sized wind turbines can generate power up to $10 \mathrm{kw}$, while that ranges from 10 to $100 \mathrm{kw}$ for medium ones. Large sizes are able to generate more than $100 \mathrm{kw}$ (RC Bansal, 2002). Consequently, since the turbines applied for supplying the electricity needs of the household/commercial and agricultural sectors are able to generate at most the power of $10 \mathrm{kw}$, they are regarded as small sized. Large sized turbines are not recommended for this sector due to economic aspects. In fact, they cause more installation costs, while supplying only a portion of the electrical energy required by each family. Therefore, the kind of turbine utilized for these sectors needs to be in correspondence with families' income and the reasonable level of required power. A convertor is commonly used to transform electricity generated by turbine from direct current (DC) to alternative current (AC). Furthermore, an energy storage system is attached to the turbine to save extra generated energy to eliminate power shortage when there is virtually no wind blowing. However, in order to ensure a permanent electricity supply for the consumer, it is necessary to attach an energy storage system, such as a battery, to the WECS. The essential role of the storage system is to remedy the wind fluctuation and then to ensure balance between unpredictable wind turbine power generation and the consumer demand $(\mathrm{Du}$ Wenjuan, 2011, JK Kaldellis, 2008). Therefore, in this paper it is assumed that a WECS comprises all parts including turbine generator, convertor and storage system.

Generally, the quantity of electricity generated by wind turbines in a particular region depends on turbine characteristics and geographical conditions and climate of the region (HS Bagiorgas, 2007, Achraf Abdelkafi, 2013). Turbine characteristics include turbine rated power, rotor diameter, and the height of turbine hub. Geographical conditions regards the amount of sunlight, heat radiation, height from sea level, and the extent of rugged areas in a given region or generally all the parameters influencing wind 
speed in the region (S Clarke, 2003). In fact, all of the above attributes are parameters affecting total energy generated by WECS. Among literatures published in this field, in some issues economic analysis of WECS and/or sensitivity analysis of total output energy from the WECS are reflected (AS Ahmed Shata, 2008, Shafiqur Rehman, 2003). In some others, roles of several components of WECS in the extent of wind speed utilization is considered (Ali Naci Celik, 2003, S Rehman, 2003). But in this paper, fundamental parameters affecting CPU are distinguished and a simple process is introduced as well, to select a WECS which supplies regular amount of consumed power and is economically desirable.

\section{Decision-making process}

This process, as a draft of the paper contribution demonstrated by fig. 1, is discussed in order that consumers can nominate different WECSs and select the one having the best consistency. It includes a step by step procedure that each step requires information from the former. This process is described in the order as below.

Step 1: Calculating CPU from the bill: As usual, the total price and amount of consumed power are written in the bill. So, consumer is able to calculate CPU of electricity that has been consumed, by dividing the first one to the second.

Step 2: Determining $H$ and $D$ : these parameters are symbols of hub height and rotor diameter of wind turbine, respectively. Since some classical equations should be used to determine CPU, an easy relation between CPU and two parameters $\mathrm{H}$ and $\mathrm{D}$ is determined in this step. These two parameters are distinguished as the basic factors affecting CPU. According to CPU analysis rather than different values of $\mathrm{H}$ and $\mathrm{D}$ for four locations with distinctive wind energy potential, the relation is estimated with high correlation coefficient. Therefore, $\mathrm{H}$ and $\mathrm{D}$ could be evaluated using this relation whenever the value of CPU is known. Estimation of this relation and performed analysis are described completely in section 3 .
Step 3: Defining WECS properties: having the amount of $\mathrm{H}$ and $\mathrm{D}$ and using some classical equations which are presented in the final sub-sections of section 2, characteristics of WECS are achievable. In fact, we nominate a WECS in this step and define its characteristics considering values of the both parameters using classical equations. The mentioned characteristics are system element's properties such as turbine size, storage capacity and so on. Furthermore, system attributes consist of output energy, capacity factor and other information.

Step 4: Determining investment cost: using technical information of WECS, market prices of each system elements could be achievable. Therefore, investment cost could be determined based on costs of wind turbine, storage system, convertor, cables and all things required to set up the system.

Step 5: Feasibility check: in this step, consumer verifies all aspects of nominated WECS in order to conform to their favorite criteria. So, WECS is nominated technically through step 2 and 3 and consumer doesn't have any role to select technical information of WECS. This work will be done referring to economics, taking into account other factors such as generator size or occupied space, vibration and produced noises or even system warranty.

Step 6: Final decision: if nominated WECS properties meet consumer preferences, this process will be finished and WECS is then prepared to set up. If not, another WECS is nominated, going back to step 2 so as to define other values for $\mathrm{H}$ and $\mathrm{D}$ and all the above steps will be repeated.

It should be noticed that the two equations, in fact, configures a surface in 3D space which exhibits numerous points. But not all the points could be selected, since small wind turbines have standard range of rotor diameters and hub heights. Consequently, there will be a set of distinct $\mathrm{H}$ and D values, every pair of which specifies a WECS.
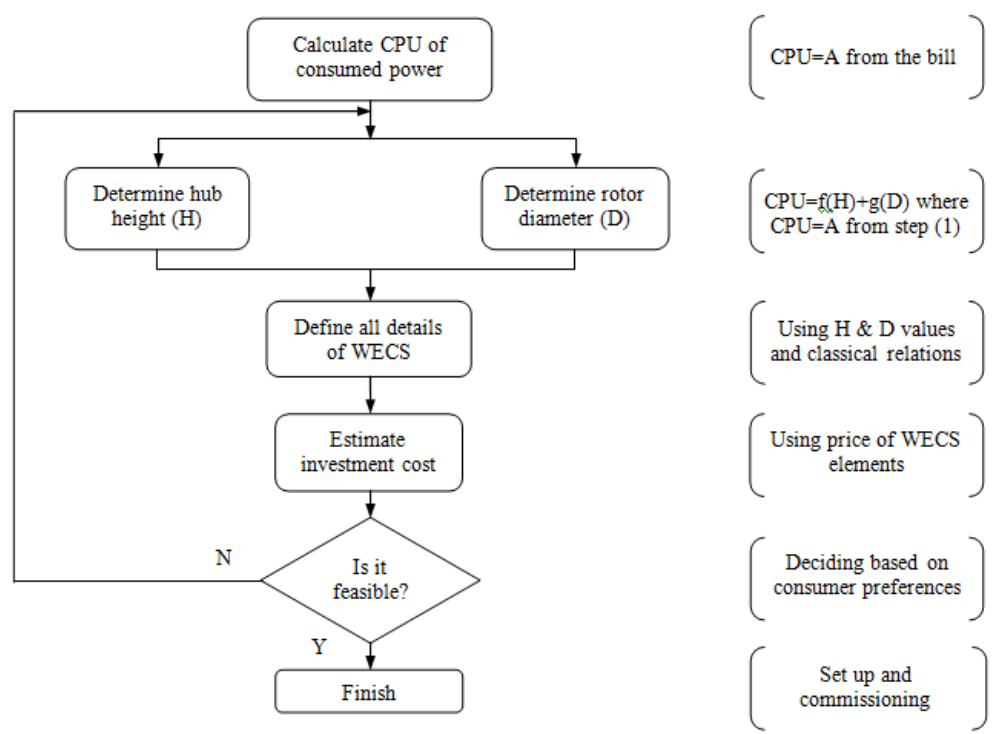

Figure 1. Schematic of decision-making process for definning wecs 
Arriving at the end of the process, since characteristics of selected WECS have been defined based on the amount of power used by consumer and climate circumstances of the place of living, WECS will be adapted technically and economically. In this respect, it should be considered that the process is not functioned as minimizing $\mathrm{CPU}$, enhancing efficiency of generation system or optimizing any of system parameter. In fact, this process suggests different WECS considering CPU value calculated from the bill and helps consumer to choose their favourite generation system using the relation as an applicable tool.

\section{Wind Parameters Estimation}

The country of Iran has an area of 1,648,195 $\mathrm{km}^{2}$, with a population of about 77 million based on the latest census in 2009, 53 million of which live in the urban areas and 24 million in the rural (Statistical Centre of Iran, 2010). Having rich fossil resources, this country is a member of OPEC (Organization of Petroleum Exporting Countries) and a major exporter of both oil and natural gas to all over the world. The share of oil and natural gas of Iran, based on energy structure of the country, is $44 \%$ and $54 \%$ of the total energy, respectively (IEA, (World energy outlook), 2010).

The ecological and geographical circumstances have caused beneficial condition in utilization of renewable energies. Nowadays, power generation from renewable sources such as hydro, solar and wind is performed noticeably. In special, in the wind power generation field, with regards to the wind energy classification carried out by
America's energy department, in the $7^{\text {th }}$ ranking of this classification many of Iran's wind sites situated in the 800-2000 $\left(\mathrm{W} / \mathrm{m}^{2}\right)$ range (Amir Hossein Ghorashi, 2011). Referring to different benefits of wind power energy and availability of its preconditions in Iran, establishment and development of wind power stations have salient growth. For example in recent years, Iran's wind capacity was estimated at about $6500 \mathrm{MW}$ (Dawud Fadai, 2007). This potential has resulted in many political advantages due to power generation and supplying to the national or international networks and has created job opportunities in the country.

Due to changes in wind speed in different areas, Weibull distribution is used for estimation of wind energy potential. Studies in the past matched the Weibull distribution and experimental data closely (D Poje, 1988, Reinhard Madlener, 2013). In order to estimate Weibull parameters, as shape and scale, and also gaining high precision in calculations, four locations with various climates and geographical conditions are nominated. These are named as Morche-Khort, Jarandagh, Nehbandan and Hadadeh that are at Esfahan, Ghazvin, Khorasan-e-Jonoubi and Semnan provinces, respectively. In fig. 2 which demonstrates wind atlas of Iran at 40 meter height, position of these locations is obvious.

According to the information gained from an anemometer installed in the height of 10 meter above the sea level, Weibull parameters are determined with respect to (1-4) (MA AL-Fawzan, 2000). Average wind speed in locations, reported monthly and annually, is presented in table 1 .

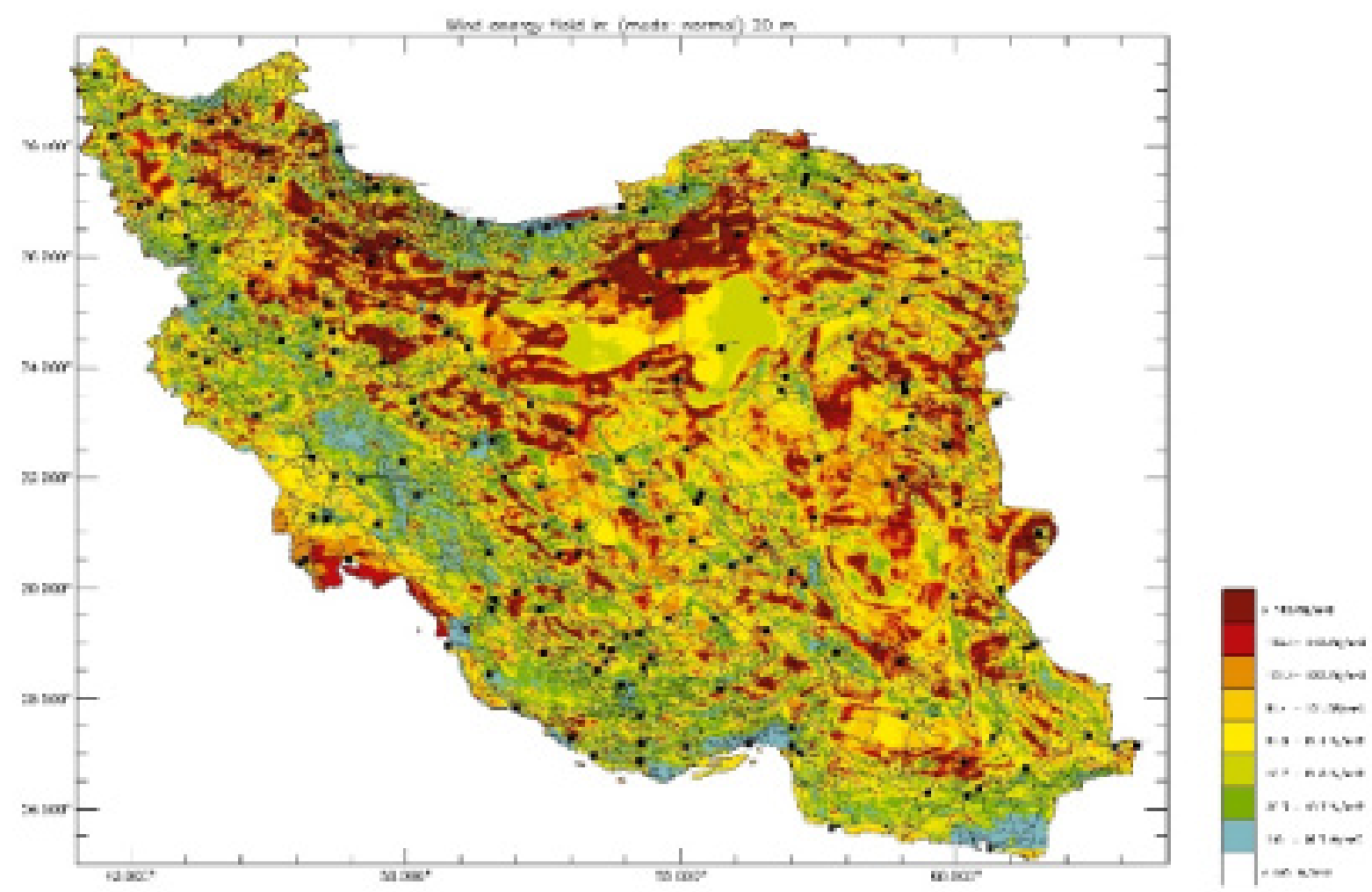

Figure. 2 Iran wind atlas demonstrating wind potential at 40 meter hieght (renewable energy organization of iran, 2010). applied symbols $\square, \circ, \diamond$ and $\delta$ refer to Jarandagh, Hadadeh, Morche-Khort and Nehbandan respectively 
Table 1. Average wind speed of the four location at $10 \mathrm{~m}$ height

\begin{tabular}{|c|c|c|c|c|}
\hline & Jarandagh & Nehbandan & Hadadeh & Morche-Khort \\
\hline January & 1.11 & 0.93 & 1.21 & 3.92 \\
\hline February & 2.02 & 3.58 & 2.78 & 5.18 \\
\hline March & 4.62 & 5.92 & 5.34 & 7.01 \\
\hline April & 7.22 & 4.09 & 4.78 & 4.98 \\
\hline May & 5.23 & 2.3 & 1.89 & 3.08 \\
\hline June & 4.52 & 2.99 & 0.84 & 2.41 \\
\hline July & 3.97 & 3.8 & 1.02 & 0.44 \\
\hline August & 3.73 & 5.56 & 3.46 & 3.07 \\
\hline September & 5.74 & 7.13 & 7.19 & 4.94 \\
\hline October & 7.04 & 6.03 & 5.75 & 5.54 \\
\hline November & 3.60 & 3.25 & 3.87 & 3.20 \\
\hline December & 2.18 & 1.12 & 2.48 & 3.14 \\
\hline Annual & 4.25 & 3.89 & 3.38 & 3.91 \\
\hline
\end{tabular}

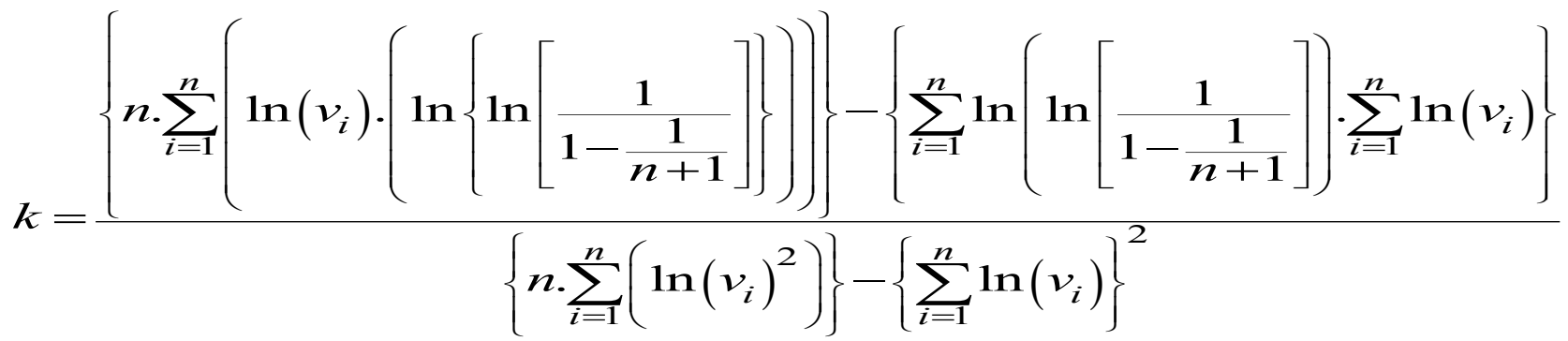

$$
\bar{v}=\frac{1}{n} \sum_{i=1}^{n} \ln \left\{\ln \left[\frac{1}{\left(1-\frac{i}{n+1}\right)}\right]\right\}
$$

In (1) and (2), " $\mathrm{v}_{\mathrm{i}}$ " stands for the wind speed of $i^{\text {th }}$ members of total gained data as " $\mathrm{n}$ ". Symbols " $\mathrm{k}$ " and "c" regard shape and scale parameters of wind speed Weibull distribution, respectively. Considering above equations, values of parameters " $\mathrm{k}$ " and "c" are calculated as mentioned in table 2 .

Table 2. Values of weibull distribution of wind speed at the four locations

\begin{tabular}{|c|c|c|c|c|}
\hline & Jarandagh & Nehbandan & Hadadeh & Morche-Khort \\
\hline $\mathrm{k}$ & 1.91 & 1.69 & 1.5 & 1.44 \\
\hline $\mathrm{c}$ & 6.12 & 5.68 & 5.12 & 6.07 \\
\hline
\end{tabular}

$$
P=0.3925 D^{2} V^{3}
$$

\section{Turbine Power Calculation}

Turbine power generally refers to the amount of electrical energy that can be generated by a turbine in a specific time interval. Wind speed is a fundamental element that has a direct relationship with turbine power (i.e. the more powerful the blowing winds are, the more potential has the turbine to generate electricity). Turbine size also affects its throughput power as to the length of blades. Long blades have broader touching surface exposed to the blowing winds and hence the rotation speed enhances. Considering what mentioned above, the power of a turbine can be calculated by (5) with regards to the wind speed and the touching surface the wind has with the blades (Ahmet Z. Sahin, 1998).

$$
P=\frac{E}{\Delta t}=\frac{1}{2} \rho A V^{3}
$$

In (5), "P" is the generated power, calculated on the basis of watt (w), "V" is the speed of wind blow and "A" stands for the area where the wind turbine blades cover. According to what is shown in fig. 2, this area is formed by rotation of turbine blades in a circular mode; furthermore, " $\rho$ " regards air density which in this paper is equal to 1 and also is assumed to be fixed for different heights. This assumption leads the error of estimating wind blow to decrease to lower than 5\% (DA Barber, 1977). So, (5) is rewritten to result in (6).

$$
P=0.3925 D^{2} V^{3}
$$

Note that in (6), "D" indicates the diameter of turbine rotor which is equivalent to the diameter of the area supported by the rotation of turbine blades, exposing to the blowing winds.

Other attributes of a wind turbine are rated power $\left(\mathrm{P}_{\mathrm{r}}\right)$, 
minimum wind speed at which the turbine can generate electricity $\left(\mathrm{V}_{\mathrm{i}}\right)$, maximum wind speed at which the turbine is able to generate the greatest rate of energy by its maximum power $\left(\mathrm{V}_{0}\right)$, and rated speed $\left(\mathrm{V}_{\mathrm{r}}\right)$. Notice that, the reduction in throughput power of turbine in intense winds prevents blades from rotating appropriately. Thus, the turbine efficiency and the power generated decrease. In many literatures, " $\mathrm{P}_{\mathrm{r}}$ " is used for estimating generated power from wind turbine (Shafiqur Rehman, 2003, AS Ahmed Shata, 2006). But referring to determination of energy generated by WECS using wind speed, taking into account variability of wind speed, it is better that " $P$ " resulting from " $V$ ", apply in this way. So, to calculate " $\bar{P}$ " according to (6), " $V^{3}$ " should be calculated based on (7) (BK Gupta, 1986).

$$
\overline{V^{3}}=\left[\frac{\Gamma\left(1-\frac{3}{k}\right)}{\Gamma^{3}\left(1+\frac{1}{k}\right)}\right] \overline{-}^{3}
$$

In (7), " $\Gamma$ " stands for a Gamma function and " $V^{3}$ " is the third power of average wind speed. According to what mentioned in (1-4), " $V$ " is a function of Weibull parameters of the wind speed. Therefore, (7) is rewritten to result in (8).

$$
\bar{V}^{3}=c^{3} \Gamma\left(1+\frac{3}{k}\right)
$$

Since the quantity of Gamma function in (8) equals to 2 approximately, " $P$ " can be calculated using the (9) which can be rewritten by substituting " $\stackrel{-}{V}$ " from (6).

$$
\bar{P}=0.785 D^{2} c^{3}
$$

According to (9), “ $P$ " is influenced by the scale parameter of Weibull distribution and rotor diameter.

\section{Evaluation of CPU}

The CPU is an underlying element in choosing a WECS, which attracts an especial attention since it looks for exploiting small wind turbines for household/commercial and agricultural consumptions. To calculate the CPU, first present value of WECS costs and then the total amount of generated power should be determined. In most papers dealing with this issue, " $\mathrm{P}_{\mathrm{r}}$ " is used to calculate the amount of power generated and the CPU, as well (HS Bagiorgas, 2007, AS Ahmed Shata, 2006). But since calculating the power generated from the turbine is done based on wind speed, which is a variable, it is better to use " $P$ " as an appropriate criteria. In fact, wind speed varies due to geographical circumstances of installation region and also the hub height of turbine, during day and night hours. It can be inferred from (6) that the variability of wind speed results in variability of power generated by turbine; consequently, using " $\mathrm{P}_{\mathrm{r}}$ " to estimate the CPU, which is not influenced by changes in WECS, cannot be justified logically. The CPU is calculated according to $(10)$ :

$$
C P U=\frac{P V C}{E_{\text {out }}}
$$

In (10), PVC stands for the Present Value of WECS Cost and " $E_{\text {out }}$ " indicates total output energy from the wind turbine, which is calculated as follows.

Total output of electrical energy is defined as (11), based on the maximum capacity of the turbine and the amount of energy that it can generate.

$$
E_{\text {out }}^{-}=C_{f} \stackrel{-}{E}
$$

In (11), " $\mathrm{C}_{\mathrm{f}}$ " is turbine capacity factor and " $\bar{E}$ " regards the average amount of energy that can be generated or average output energy. The capacity factor of a wind turbine represents the actual energy output for the given system and conditions as a proportion of a rated power output over an entire rate (RH Crawford, 2009). Value of this factor is variable in the range from 10 to $50 \%$ and in modern wind machines this will reach 20-35\% (Manfred Lenzen, 2002). The capacity factor of each wind turbine can be calculated using (12) (A El-Mallah, 1989).

$$
C_{f}=\frac{\exp \left(-\left(\frac{V_{i}}{c}\right)^{k}\right)-\exp \left(-\left(\frac{V_{r}}{c}\right)^{k}\right)}{\left(\frac{V_{r}}{c}\right)^{k}-\left(\frac{V_{i}}{c}\right)^{k}}-\exp \left(-\left(\frac{V_{o}}{c}\right)^{k}\right)
$$

In (12), " $k$ " and "c" are the parameters of wind speed Weibull distribution and " $\mathrm{V}_{\mathrm{i}}$ ", " $\mathrm{V}_{\mathrm{r}}$ " and " $\mathrm{V}_{\mathrm{o}}$ " refer to minimum, rated, and maximum speed of the wind, respectively.

For the 20 year life cycle assumed in this paper, the average output energy, " $E$ ", considering " $P$ " should be defined according to the investigation period as shown in (13).

$$
\stackrel{-}{E}=20 \times 365 \times 24 \times \stackrel{-}{P}
$$

In order to define CPU, it is necessary to calculate PVC of WECS. Present value technique is one of the most important and premium techniques for assessing projects economically. To specify PVC, all costs relevant to WECS should be categorized first and then each one should be determined individually. These are divided into purchasing, accessories, establishment, and set up costs. Of course, operational and maintenance costs are incurred during the utilization. Therefore, PVC is calculated according to the (14) (HS Bagiorgas, 2007), in which, " $t$ " shows the life cycle (20 years) and " $i$ " is the index of interest rate which equals to $15 \%$.

$$
P V C=I+C_{\text {omr }}\left[\frac{(1+i)^{t}-1}{i(1+i)^{t}}\right]-S\left[\frac{1}{(1+i)^{t}}\right]
$$

Each of the cost types used in (14) and the assumptions are explained below.

"I": Investment costs including equipment and facilities' 
(turbine, converter, and battery)costs, execution costs (to establish the whole system), and connection costs (i.e. the expenditure for connecting cables and so on)which are considered as a fixed portion of wind price $(30 \%)$.

" $\mathrm{C}_{\text {omr }}$ ": encompasses operational and maintenance costs of utilizing WECS in the given period. It is calculated as a percentage of turbine annual cost (which can be specified by division of turbine price by its useful life).

"S": regards scrap value that the whole WECS has at the end of its life. Scrap value is specified based on a fixed portion of establishment and purchase costs of turbine $(10 \%)$.

Therefore, by clarifying values of both PVC and " $\mathrm{E}_{\text {out }}$ ", amount of CPU of a WECS is accessible.

In the next section, methodology of determination and evaluation of mathematical equations that demonstrate relation between CPU and rotor diameter and also hub height is explained.

\section{Formulation Mathematical Relation}

The purpose of this section is development of a relation with the help of which all characteristics of WECS will be defined, attending families' income influence on payment

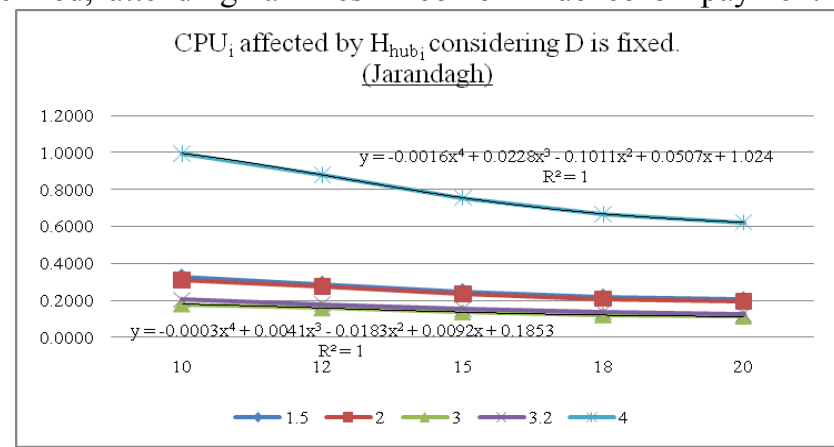

Figure 3

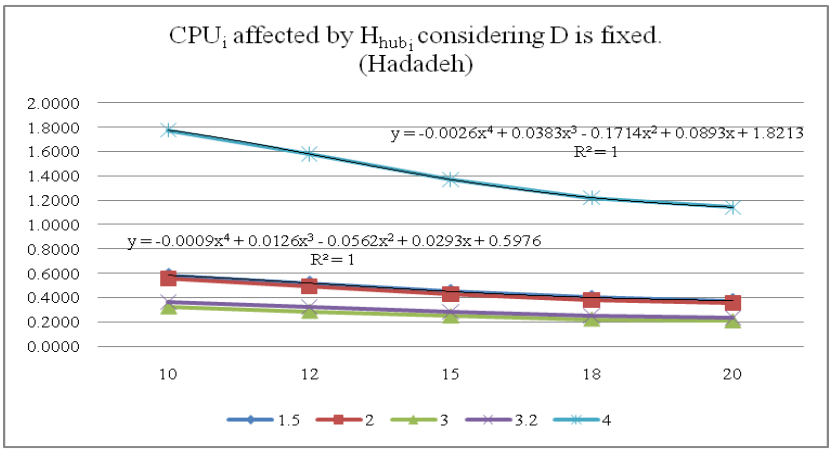

Figure 5 for CPU. According to (10), CPU depends on PVC, on one hand and " $\mathrm{E}_{\text {out }}$ " on the other hand. PVC is influenced by physical characteristics of WECS, whose most important part is the wind turbine. Total output of the electrical energy is calculated due to the average energy which is generated by average power of turbine depending on rotor diameter and Weibull distribution scale parameters of wind speed according to (9). In other words, it can be stated that the CPU depends on two parameters, turbine rotor diameter, used to specify turbine size, and Weibull distribution scale parameter of wind speed. As the scale parameter is a function of the height from the sea level, its value varies by different heights based on (15) (S Olayinka Ohunakin, 2012):

$$
c_{2}=c_{1}\left(\frac{h_{2}}{h_{1}}\right)^{\frac{1}{7}}
$$

In (15), "c $\mathrm{c}_{1}$ " pertains to the quantity of scale parameter of wind speed distribution in the height " $\mathrm{h}_{1} "=10 " \mathrm{~m}$ " and " $\mathrm{c}_{2}$ " refers to the same issue in the height " $\mathrm{h}_{2}$ " which should be calculated. Therefore, changes in the rotor diameter and the hub height cause changes in PVC and " $\mathrm{E}_{\text {out }}$ " and finally CPU.

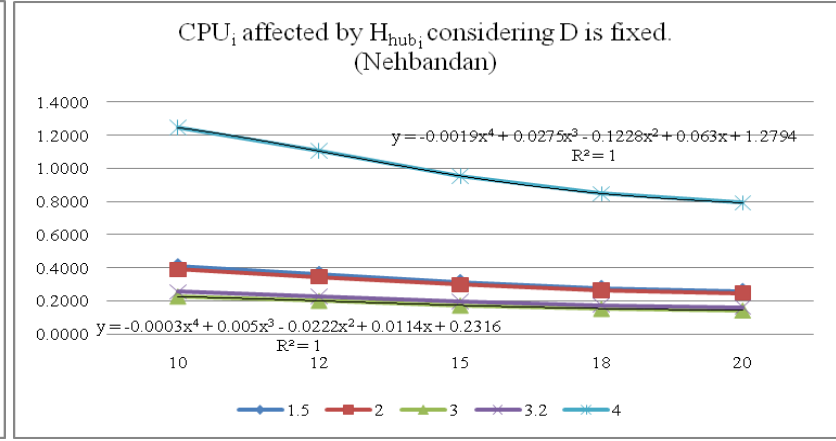

Figure 4

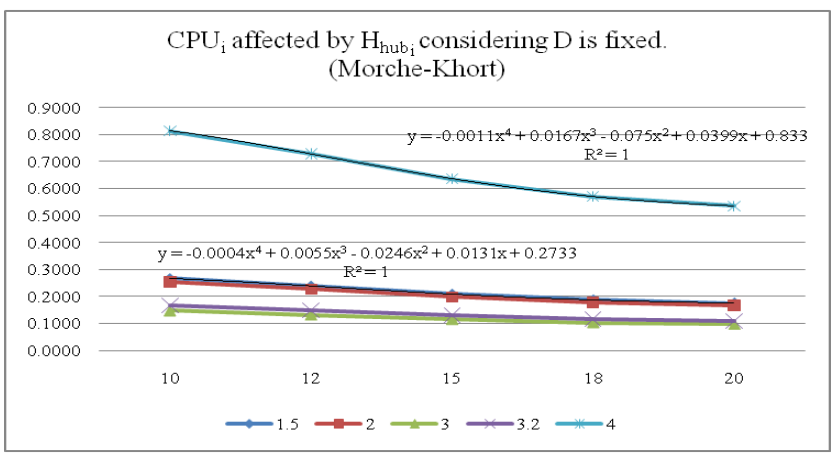

Figure 6

Figure 3-6. Cpui Affected By Hi Considering D to be fixed for the locations Jarandagh, Nehbandan, Hadadeh and Morche-Khort respectively 
Recognizing the equation, relation between CPU and hub height is first determined considering changes in hub height, assuming rotor diameter to be fixed. For sensitivity analysis of estimation, five various turbines (with various rotor diameters and hub heights) at each four locations are employed (tables 4-7). Specifications of the turbines are summarized in table 3 (Turbine prices website, Proven turbine prices website, Fortis turbine prices website, Talon turbine prices website).

CPU is reduced considering the results demonstrated by fig. 3-6, which reflect behavior of CPU affected by increasing the value of $\mathrm{H}$ for four locations, assuming rotor diameter to be fixed. Referring to each curve of these figures, a four degree polynomial approximation can be concluded. This approximation is so efficient that it provides a higher correlation coefficient for this relation, compared with the other approximations $(\approx 1)$. In order to reduce error in estimation, because of noticeable distance between curves drawn for $\mathrm{H}=4$, the relation is formulated for $\mathrm{H} \leq 3.2 \mathrm{~m}$. Thus,

result of this propriety can be showed as (16).

$$
C P U=-0.0005 H^{4}+0.0068 H^{3}-0.0302 H^{2}+0.0156 H+0.319(16)
$$

Table 3. Specifications of five small wind turbines

\begin{tabular}{|c|c|c|c|c|}
\hline $\operatorname{Pr}(\mathrm{kw})$ & $\mathrm{D}(\mathrm{m})$ & $\mathrm{Vi}(\mathrm{m} / \mathrm{s})$ & $\mathrm{Vr}(\mathrm{m} / \mathrm{s})$ & $\mathrm{Vo}(\mathrm{m} / \mathrm{s})$ \\
\hline 2 & 1.5 & 2.1 & 12 & 40 \\
\hline 3 & 2 & 2.1 & 12 & 40 \\
\hline 5 & 3. & 1.2 & 12 & 60 \\
\hline 7 & 3.2 & 2.1 & 12 & 65 \\
\hline 10 & 4 & 2.1 & 12 & 65 \\
\hline
\end{tabular}

Now, the formula is derived for different Rotor diameters. Results are shown in fig. 7-10. To define the relationship between CPU and rotor diameter, four degree polynomial relations led to better approximations (with correlation coefficient approximately equal to 1 ). The relation of this step is depicted by (17).

$$
C P U=0.142 D^{4}-0.097 D^{3}+0.157 D^{2}-0.0612 D+0.2981
$$

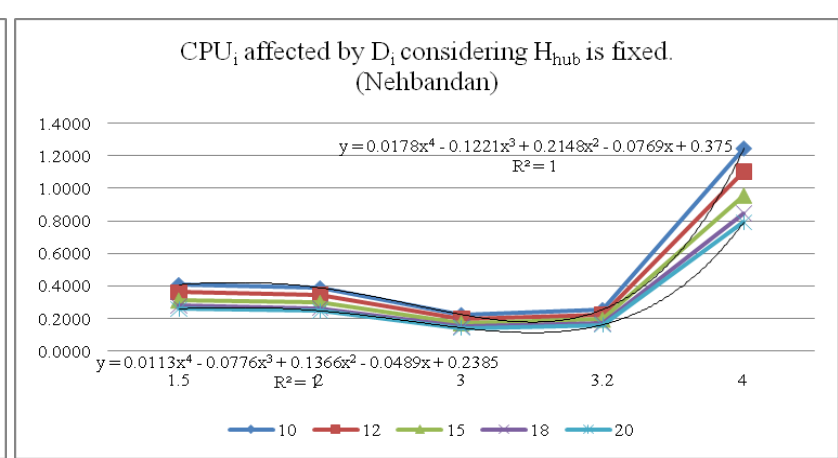

Figure 7

Figure 8

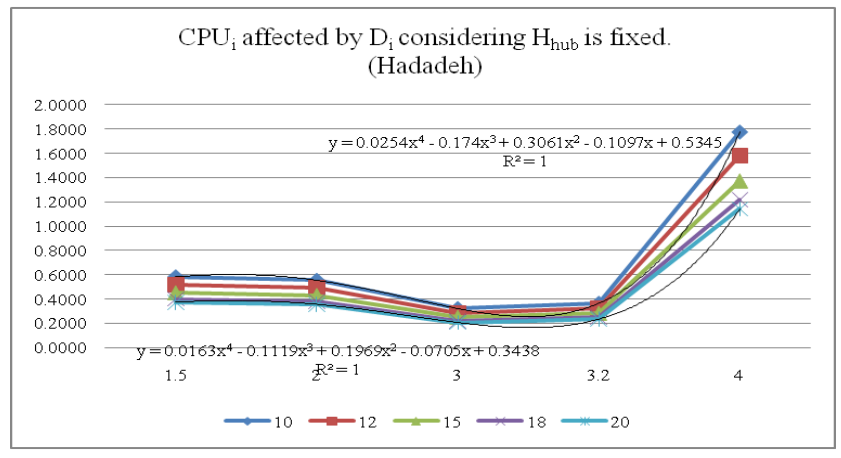

Figure 9

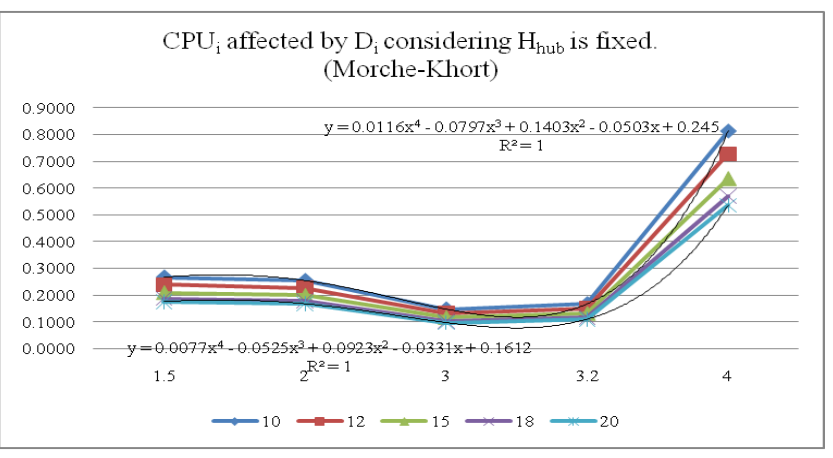

Figure 10

Figure 7-10. Cpui affected By Di Considering H To de fixed for the locations Jarandagh, Nehbandan, Hadadeh and Morche-Khort respectively 
Table 4. Calculation of CPU for the location Jarandagh

\begin{tabular}{|c|c|c|c|c|c|c|c|c|c|c|c|c|c|c|}
\hline Rated Power & $\mathbf{H}_{\text {hub }}(\mathrm{m})$ & D (m) & $\underset{(\mathrm{m} / \mathrm{s})}{\mathrm{C}}$ & $\mathbf{k}$ & $\mathbf{V}_{\mathbf{i}}$ & $\mathbf{V}_{\mathbf{r}}$ & $\mathbf{V}_{\mathbf{0}}$ & $\mathbf{C}_{\mathrm{f}}$ & $\overline{\mathbf{P}}(\mathbf{w})$ & $\overline{\mathbf{E}}(\mathbf{k w})$ & $\mathbf{E}_{\text {out }}(\mathbf{k w})$ & $\operatorname{PVC}(€)$ & $\mathrm{CPU}(€ / \mathbf{k w})$ & CPU (Rial/kw) \\
\hline \multirow{5}{*}{2} & 10 & \multirow{5}{*}{1.5} & 6.1 & \multirow{5}{*}{1.91} & \multirow{5}{*}{1.2} & \multirow{5}{*}{12} & \multirow{5}{*}{40} & 0.260 & 404.9 & 70931.7 & 18449.7 & \multirow{5}{*}{6022.0} & 0.3264 & 5548.8 \\
\hline & 12 & & 6.3 & & & & & 0.272 & 437.8 & 76696.5 & 20897.2 & & 0.2882 & 4899.0 \\
\hline & 15 & & 6.5 & & & & & 0.288 & 481.7 & 84393.3 & 24311.1 & & 0.2477 & 4211.0 \\
\hline & 18 & & 6.7 & & & & & 0.301 & 520.8 & 91252.1 & 27483.5 & & 0.2191 & 3724.9 \\
\hline & 20 & & 6.8 & & & & & 0.309 & 544.9 & 95467.0 & 29489.9 & & 0.2042 & 3471.5 \\
\hline \multirow{4}{*}{3} & 10 & \multirow{4}{*}{2} & 6.1 & \multirow{4}{*}{1.91} & \multirow{4}{*}{1.2} & \multirow{4}{*}{12} & \multirow{4}{*}{40} & 0.260 & 719.8 & 126100.9 & 32799.5 & \multirow{4}{*}{10189.2} & 0.3107 & 5281.1 \\
\hline & 12 & & 6.3 & & & & & 0.272 & 778.2 & 136349.3 & 37150.6 & & 0.2743 & 4662.6 \\
\hline & 18 & & 6.7 & & & & & 0.301 & 925.9 & 162226.0 & 48859.5 & & 0.2085 & 3545.2 \\
\hline & 20 & & 6.8 & & & & & 0.309 & 968.7 & 169719.2 & 52426.4 & & 0.1944 & 3304.0 \\
\hline \multirow{5}{*}{5} & 10 & \multirow{5}{*}{3} & 6.1 & \multirow{5}{*}{1.91} & \multirow{5}{*}{1.2} & \multirow{5}{*}{12} & \multirow{5}{*}{60} & 0.260 & 1619.4 & 283726.9 & 73798.8 & \multirow{5}{*}{13287.9} & 0.1801 & 3061.0 \\
\hline & 12 & & 6.3 & & & & & 0.272 & 1751.1 & 306785.9 & 83588.8 & & 0.1590 & 2702.5 \\
\hline & 15 & & 6.5 & & & & & 0.288 & 1926.8 & 337573.4 & 97244.2 & & 0.1366 & 2323.0 \\
\hline & 18 & & 6.7 & & & & & 0.301 & 2083.4 & 365008.5 & 109933.9 & & 0.1209 & 2054.8 \\
\hline & 20 & & 6.8 & & & & & 0.309 & 2179.6 & 381868.1 & 117959.4 & & 0.1126 & 1915.0 \\
\hline \multirow{4}{*}{7} & 10 & \multirow{4}{*}{3.2} & 6.1 & \multirow{4}{*}{1.91} & \multirow{4}{*}{1.2} & \multirow{4}{*}{12} & \multirow{4}{*}{65} & 0.260 & 1842.6 & 322818.2 & 83966.7 & \multirow{4}{*}{17150.0} & 0.2042 & 3472.2 \\
\hline & 12 & & 6.3 & & & & & 0.272 & 1992.3 & 349054.1 & 95105.5 & & 0.1803 & 3065.5 \\
\hline & 18 & & 6.7 & & & & & 0.301 & 2370.4 & 415298.6 & 125080.3 & & 0.1371 & 2330.9 \\
\hline & 20 & & 6.8 & & & & & 0.309 & 2479.9 & 434481.0 & 134211.6 & & 0.1278 & 2172.3 \\
\hline \multirow{5}{*}{10} & 10 & & 6.1 & & & & & 0.260 & 719.8 & 126100.9 & 32799.5 & & 0.9948 & 16911.1 \\
\hline & 12 & & 6.3 & & & & & 0.272 & 778.2 & 136349.3 & 37150.6 & & 0.8783 & 14930.5 \\
\hline & 15 & 4 & 6.5 & 1.91 & 1.2 & 12 & 65 & 0.288 & 856.4 & 150032.6 & 43219.6 & 32628.0 & 0.7549 & 12833.9 \\
\hline & 18 & & 6.7 & & & & & 0.301 & 925.9 & 162226.0 & 48859.5 & & 0.6678 & 11352.5 \\
\hline & 20 & & 6.8 & & & & & 0.309 & 968.7 & 169719.2 & 52426.4 & & 0.6224 & 10580.1 \\
\hline
\end{tabular}


Table 5. Calculation of CPU for the location Nehbandan

\begin{tabular}{|c|c|c|c|c|c|c|c|c|c|c|c|c|c|c|}
\hline Rated Power & Hhub (m) & D (m) & $\underset{(\mathrm{m} / \mathbf{s})}{\mathbf{C}}$ & $\mathbf{k}$ & $\mathbf{V i}$ & $\mathbf{V r}$ & Vo & Cf & $\overline{\mathbf{P}}(\mathbf{w})$ & $\overline{\mathbf{E}}(\mathbf{k w})$ & Eout (kw) & $\operatorname{PVC}(€)$ & CPU $(€ / \mathbf{k w})$ & CPU (Rial/kw) \\
\hline \multirow{4}{*}{2} & 10 & \multirow{4}{*}{1.5} & 5.7 & \multirow{4}{*}{1.69} & \multirow{4}{*}{1.2} & \multirow{4}{*}{12} & \multirow{4}{*}{40} & 0.260 & 323.7 & 56706.3 & 14739.1 & \multirow{4}{*}{6022.0} & 0.4086 & 6945.8 \\
\hline & 12 & & 5.8 & & & & & 0.271 & 350.0 & 61314.9 & 16619.4 & & 0.3623 & 6159.9 \\
\hline & 18 & & 6.2 & & & & & 0.297 & 416.4 & 72951.4 & 21649.0 & & 0.2782 & 4728.8 \\
\hline & 20 & & 6.3 & & & & & 0.304 & 435.6 & 76321.0 & 23174.3 & & 0.2599 & 4417.6 \\
\hline \multirow{4}{*}{3} & 10 & \multirow{4}{*}{2} & 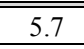 & \multirow{4}{*}{1.69} & \multirow{4}{*}{1.2} & \multirow{4}{*}{12} & \multirow{4}{*}{40} & 0.260 & 575.4 & 100811.2 & 26202.8 & \multirow{4}{*}{10189.2} & 0.3889 & 66610.6 \\
\hline & 12 & & 5.8 & & & & & 0.271 & 622.2 & 109004.3 & 29545.6 & & 0.3449 & 5862.7 \\
\hline & 18 & & 6.2 & & & & & 0.297 & 740.2 & 129691.4 & 38487.2 & & 0.2647 & 4500.6 \\
\hline & 20 & & 6.3 & & & & & 0.304 & 774.4 & 135681.8 & 41198.7 & & 0.2473 & 4204.4 \\
\hline \multirow{5}{*}{5} & 10 & \multirow{5}{*}{3} & 5.7 & \multirow{5}{*}{1.69} & \multirow{5}{*}{1.2} & \multirow{5}{*}{12} & \multirow{5}{*}{60} & 0.260 & 1294.7 & 226825.2 & 58956.4 & \multirow{5}{*}{13287.9} & 0.2254 & 3831.6 \\
\hline & 12 & & 5.8 & & & & & 0.271 & 1399.9 & 245259.6 & 66477.7 & & 0.1999 & 3398.1 \\
\hline & 15 & & 6.0 & & & & & 0.285 & 1540.4 & 269872.7 & 76925.0 & & 0.1727 & 2936.6 \\
\hline & 18 & & 6.2 & & & & & 0.297 & 1665.6 & 291805.7 & 86596.1 & & 0.1534 & 2608.6 \\
\hline & 20 & & 6.3 & & & & & 0.304 & 1742.5 & 305284.1 & 92697.2 & & 0.1433 & 2436.9 \\
\hline \multirow{4}{*}{7} & 10 & \multirow{4}{*}{3.2} & $\begin{array}{c}5.7 \\
\end{array}$ & \multirow{4}{*}{1.69} & \multirow{4}{*}{1.2} & \multirow{4}{*}{12} & \multirow{4}{*}{65} & \begin{tabular}{c|}
0.260 \\
\end{tabular} & 1473.0 & 258076.7 & $\begin{array}{c}67079.3 \\
\end{array}$ & \multirow{4}{*}{17150.0} & 0.2557 & 4346.3 \\
\hline & 12 & & 5.8 & & & & & 0.271 & 1592.8 & 279051.0 & 75636.9 & & 0.2267 & 3854.6 \\
\hline & 18 & & 6.2 & & & & & 0.297 & 1895.0 & 332010.0 & 98527.1 & & 0.1741 & 2959.1 \\
\hline & 20 & & 6.3 & & & & & 0.304 & 1982.6 & 347345.4 & 105468.8 & & 0.1626 & 2764.3 \\
\hline \multirow{5}{*}{10} & $\overline{10}$ & & 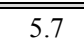 & & & & & 0.260 & 2575.4 & 10100811.2 & 26202.8 & & $\bar{~} 1.2452$ & 21168.6 \\
\hline & 12 & & 5.8 & & & & & 0.271 & 622.2 & 109004.3 & 29545.6 & & 1.1043 & 18773.6 \\
\hline & 15 & 4 & 6.0 & 1.69 & 1.2 & 12 & 65 & 0.285 & 684.6 & 119943.4 & 34188.9 & 32628.0 & 0.9543 & 16223.9 \\
\hline & 18 & & 6.2 & & & & & 0.297 & 740.2 & 129691.4 & 38487.2 & & 0.8478 & 14412.0 \\
\hline & 20 & & 6.3 & & & & & 0.304 & 774.4 & 135681.8 & 41198.7 & & 0.7920 & 13463.4 \\
\hline
\end{tabular}


Table 6. Calculation of CPU for the location Hadadeh

\begin{tabular}{|c|c|c|c|c|c|c|c|c|c|c|c|c|c|c|}
\hline Rated Power & Hhub (m) & $\mathbf{D}(\mathbf{m})$ & $\underset{(\mathrm{m} / \mathbf{s})}{\mathbf{C}}$ & $\mathbf{k}$ & $\mathbf{V i}$ & $\mathbf{V r}$ & Vo & Cf & $\overline{\mathbf{P}}(\mathbf{w})$ & $\overline{\mathbf{E}}(\mathbf{k w})$ & Eout (kw) & $\operatorname{PVC}(€)$ & CPU $(€ / \mathbf{k w})$ & CPU (Rial/kw) \\
\hline \multirow{4}{*}{2} & 10 & \multirow{4}{*}{1.5} & 5.1 & \multirow{4}{*}{1.5} & \multirow{4}{*}{1.2} & \multirow{4}{*}{12} & \multirow{4}{*}{40} & 0.249 & 237.1 & 41533.3 & 10340.5 & \multirow{4}{*}{6022.0} & 0.5824 & 9900.3 \\
\hline & 12 & & 5.3 & & & & & 0.259 & 256.3 & 44908.8 & 11623.9 & & 0.5181 & 8807.2 \\
\hline & 18 & & 5.6 & & & & & 0.282 & 305.0 & 53431.7 & 15043.9 & & 0.4003 & 6805.0 \\
\hline & 20 & & 5.7 & & & & & 0.288 & 319.1 & 55899.6 & 16078.1 & & 0.3745 & 6367.3 \\
\hline \multirow{4}{*}{3} & 10 & \multirow{4}{*}{2} & 5.1 & \multirow{4}{*}{1.5} & \multirow{4}{*}{1.2} & \multirow{4}{*}{12} & \multirow{4}{*}{40} & 0.249 & 421.4 & 73836.9 & 18383.2 & \multirow{4}{*}{10189.2} & 0.5543 & 9422.6 \\
\hline & 12 & & 5.3 & & & & & 0.259 & 455.7 & 79837.8 & 20664.7 & & 0.4931 & 8382.3 \\
\hline & 18 & & 5.6 & & & & & 0.282 & 542.2 & 94989.6 & 26744.7 & & 0.3810 & 6476.7 \\
\hline & 20 & & 5.7 & & & & & 0.288 & 567.2 & 99377.1 & 28583.4 & & 0.3565 & 6060.1 \\
\hline \multirow{5}{*}{5} & 10 & \multirow{5}{*}{3} & 5.1 & \multirow{5}{*}{1.5} & \multirow{5}{*}{1.2} & \multirow{5}{*}{12} & \multirow{5}{*}{60} & 0.249 & 948.2 & 166133.1 & 441362.1 & \multirow{5}{*}{13287.9} & 0.3213 & 5461.4 \\
\hline & 12 & & 5.3 & & & & & 0.259 & 1025.3 & 179635.0 & 46495.6 & & 0.2858 & 4858.4 \\
\hline & 15 & & 5.4 & & & & & 0.271 & 1128.2 & 197662.3 & 53607.5 & & 0.2479 & 4213.9 \\
\hline & 18 & & 5.6 & & & & & 0.282 & 1219.9 & 213726.6 & 60175.5 & & 0.2208 & 3753.9 \\
\hline & 20 & & 5.7 & & & & & 0.288 & 1276.2 & 223598.6 & 64312.6 & & 0.2066 & 3512.4 \\
\hline \multirow{4}{*}{7} & 10 & \multirow{4}{*}{3.2} & 5.1 & \multirow{4}{*}{1.5} & \multirow{4}{*}{1.2} & \multirow{4}{*}{12} & \multirow{4}{*}{65} & 0.249 & 1078.9 & 189022.5 & 477060.9 & \multirow{4}{*}{17150.0} & 0.3644 & 6195.2 \\
\hline & 12 & & 5.3 & & & & & 0.259 & 1166.6 & 204384.7 & 52901.7 & & 0.3242 & 5511.2 \\
\hline & 18 & & 5.6 & & & & & 0.282 & 1388.0 & 243173.4 & 68466.4 & & 0.2505 & 4258.3 \\
\hline & 20 & & 5.7 & & & & & 0.288 & 1452.1 & 254405.5 & 73173.4 & & 0.2344 & 3984.4 \\
\hline \multirow{5}{*}{10} & 10 & & 5.1 & & & & & 0.249 & 421.4 & 73836.9 & 18383.2 & & 1.7749 & 30173.1 \\
\hline & 12 & & 5.3 & & & & & 0.259 & 455.7 & 79837.8 & 20664.7 & & 1.5789 & 26841.7 \\
\hline & 15 & 4 & 5.4 & 1.5 & 1.2 & 12 & 65 & 0.271 & 501.4 & 87849.9 & 23825.6 & 32628.0 & 1.3695 & 23280.7 \\
\hline & 18 & & 5.6 & & & & & 0.282 & 542.2 & 94989.6 & 26744.7 & & 1.2200 & 20739.7 \\
\hline & 20 & & 5.7 & & & & & 0.288 & 567.2 & 99377.1 & 28583.4 & & 1.1415 & 19405.6 \\
\hline
\end{tabular}


Table 7. Calculation of CPU for the location Morche-khort

\begin{tabular}{|c|c|c|c|c|c|c|c|c|c|c|c|c|c|c|}
\hline Rated Power & $\mathbf{H}_{\text {hub }}(\mathbf{m})$ & D (m) & $\underset{(\mathrm{m} / \mathrm{s})}{\mathrm{C}}$ & $\mathbf{k}$ & $\mathbf{V}_{\mathbf{i}}$ & $\mathbf{V}_{\mathbf{r}}$ & $\mathbf{V}_{\mathrm{o}}$ & $\mathbf{C}_{\mathrm{f}}$ & $\overline{\mathbf{P}}(\mathbf{w})$ & $\overline{\mathbf{E}}(\mathbf{k w})$ & $\mathbf{E}_{\text {out }}(\mathbf{k w})$ & $\operatorname{PVC}(€)$ & CPU (€/kw) & CPU (Rial/kw) \\
\hline \multirow{4}{*}{2} & 10 & \multirow{4}{*}{1.5} & 6.1 & \multirow{4}{*}{1.44} & \multirow{4}{*}{1.2} & \multirow{4}{*}{12} & \multirow{4}{*}{40} & 0.326 & 395.0 & 69207.4 & 22562.2 & \multirow{4}{*}{6022.0} & 0.2669 & 4537.4 \\
\hline & 12 & & 6.2 & & & & & 0.337 & 427.1 & 74832.0 & 25209.9 & & 0.2389 & 4060.9 \\
\hline & 18 & & 6.6 & & & & & 0.362 & 508.2 & 89033.8 & 32187.3 & & 0.1871 & 3180.6 \\
\hline & 20 & & 6.7 & & & & & 0.368 & 531.7 & 93146.2 & 34278.2 & & 0.1757 & 2986.6 \\
\hline \multirow{4}{*}{3} & 10 & \multirow{4}{*}{2} & 6.1 & \multirow{4}{*}{1.44} & \multirow{4}{*}{1.2} & \multirow{4}{*}{12} & \multirow{4}{*}{40} & 0.326 & 702.3 & 123035.3 & 40110.5 & \multirow{4}{*}{10189.2} & 0.2540 & 4318.5 \\
\hline & 12 & & 6.2 & & & & & 0.337 & 759.3 & 133034.6 & 44817.5 & & 0.2273 & 3864.9 \\
\hline & 18 & & 6.6 & & & & & 0.362 & 903.4 & 158282.3 & 57221.8 & & 0.1781 & 3027.1 \\
\hline & 20 & & 6.7 & & & & & 0.368 & 945.2 & 165593.3 & 60939.1 & & 0.1672 & 2842.5 \\
\hline \multirow{5}{*}{5} & 10 & \multirow{5}{*}{3} & 6.1 & \multirow{5}{*}{1.44} & \multirow{5}{*}{1.2} & \multirow{5}{*}{12} & \multirow{5}{*}{60} & 0.326 & 1580.1 & 276829.5 & 90248.7 & \multirow{5}{*}{13287.9} & 0.1472 & 2503.0 \\
\hline & 12 & & 6.2 & & & & & 0.337 & 1708.5 & 299327.9 & 100839.4 & & 0.1318 & 2240.1 \\
\hline & 15 & & 6.4 & & & & & 0.350 & 1879.9 & 329367.0 & 115401.1 & & 0.1151 & 1957.5 \\
\hline & 18 & & 6.6 & & & & & 0.362 & 2032.7 & 356135.2 & 128749.1 & & 0.1032 & 1754.5 \\
\hline & 20 & & 6.7 & & & & & 0.368 & 2126.6 & 372584.9 & 137112.9 & & 0.0969 & 1647.5 \\
\hline \multirow{4}{*}{7} & 10 & \multirow{4}{*}{3.2} & 6.1 & \multirow{4}{*}{1.44} & \multirow{4}{*}{1.2} & \multirow{4}{*}{12} & \multirow{4}{*}{65} & 0.326 & 1797.8 & 314970.4 & 102682.9 & \multirow{4}{*}{17150.0} & 0.1670 & 2839.3 \\
\hline & 12 & & 6.2 & & & & & 0.337 & 1943.9 & 340568.6 & 114732.8 & & 0.1495 & 2541.1 \\
\hline & 18 & & 6.6 & & & & & 0.362 & 2312.8 & 405202.7 & 146487.9 & & 0.1171 & 1990.3 \\
\hline & 20 & & 6.7 & & & & & 0.368 & 2419.6 & 423918.8 & 156004.0 & & 0.1099 & 1868.9 \\
\hline \multirow{5}{*}{10} & 10 & & 6.1 & & & & & 0.326 & 702.3 & (123035.3 & 40110.5 & & 0.8135 & 13828.7 \\
\hline & 12 & & 6.2 & & & & & 0.337 & 759.3 & 133034.6 & 44817.5 & & 0.7280 & 12376.3 \\
\hline & 15 & 4 & 6.4 & 1.44 & 1.2 & 12 & 65 & 0.350 & 835.5 & 146385.3 & 51289.4 & 32628.0 & 0.6362 & 10814.7 \\
\hline & 18 & & 6.6 & & & & & 0.362 & 903.4 & 158282.3 & 57221.8 & & 0.5702 & 9693.4 \\
\hline & 20 & & 6.7 & & & & & 0.368 & 945.2 & 165593.3 & 60939.1 & & 0.5354 & 9102.2 \\
\hline
\end{tabular}


Therefore, CPU separately relates to both (16) and (17). On the other hand, if one of the two is considered to be fixed, each of the equations can be usable. But for investigating CPU behavior versus the two parameters concurrently and estimation of the relation, we have applied the mathematical laboratory software, MATLAB. First, this investigation is performed for each of the locations, whose results are exhibited in figures 11 to 14 . These four figures are respectively presented with statistical details including correlation coefficient (r-square) and sum of them duo to error (SSE) as follows.

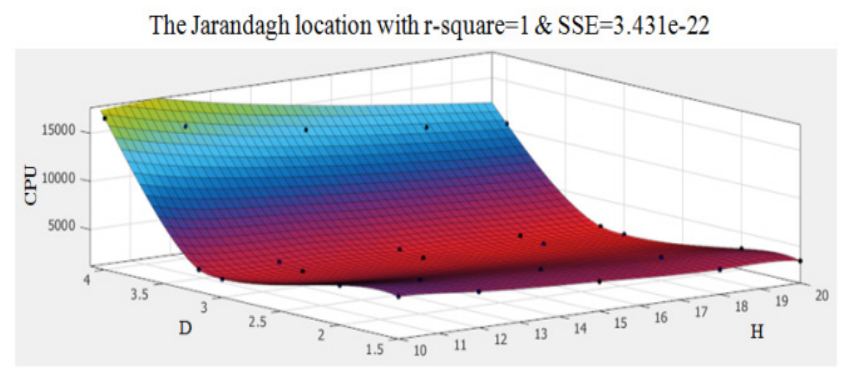

Figure 11.

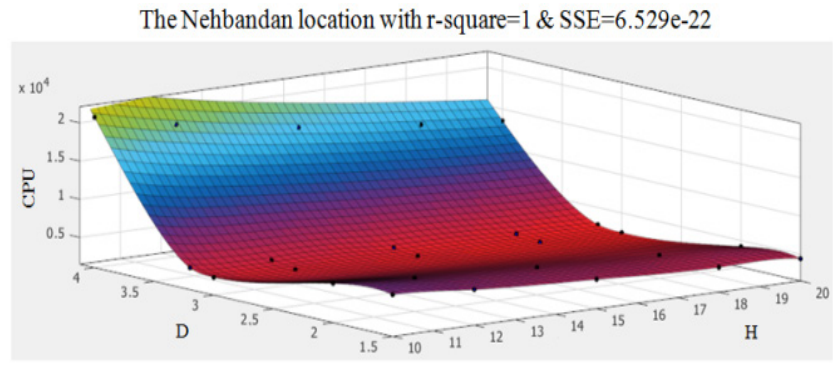

Figure 12.

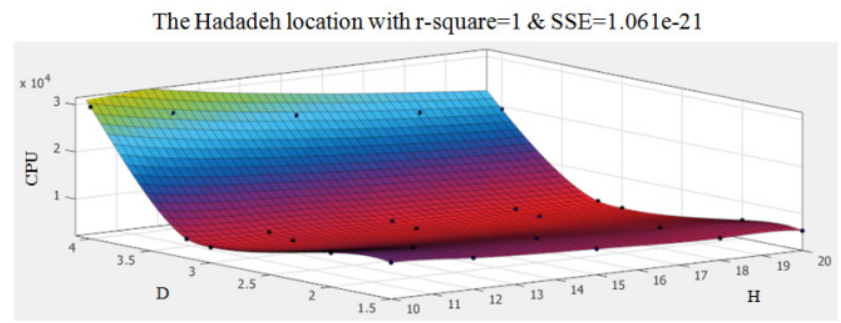

Figure 13.

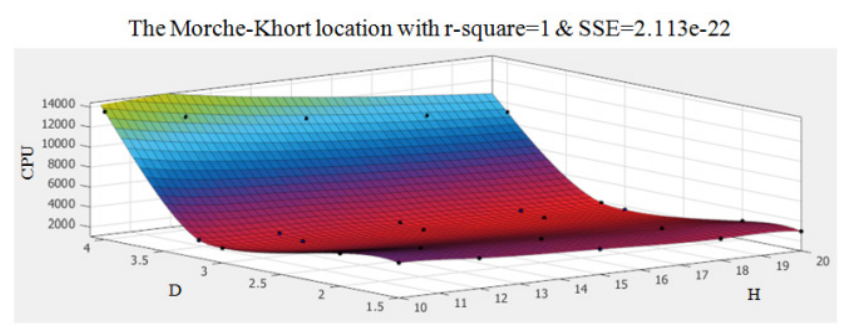

Figure 14

Figure 11-14 Cpui affected by Di Considering $\mathrm{H}$ to be fixed for the locations Jarandagh, Nehbandan, Hadadeh and Morche-Khort respectively
As it is clear, variation in value of $\mathrm{CPU}$ in relation to each of the parameters, considering value of the other parameter to be fixed, is showing precisely the same manner related to fig. 3-10 for every locations.

Since value of CPU is in change by the two parameters for every installation locations, it is necessary to define an equation including the three variables $\mathrm{CPU}, \mathrm{D}$ and $\mathrm{H}$. It should be said that because of noticeable distance between points for $\mathrm{H}=4$ comparing to each other's and the resulting decrease in estimation error, the relation is formulated for $\mathrm{H} \leq 3.2 \mathrm{~m}$. Using the MATLAB software, the equation regarding the most conformity (r-square $=0.99999$ and FitStdErr $=0.35917932$ ) is defined as below.

$$
\begin{aligned}
& \ln (C P U)=a_{1}+a_{2} D_{2}+a_{3} D(\ln (D))+a_{4} D^{3}+a_{5}(\ln (D))^{2}+a_{6} H^{0.5} \\
& +a_{7} \ln (H)+a_{8}\left(\frac{\ln (H)}{H}\right)
\end{aligned}
$$

$$
\mathrm{a}_{1}=0.40896, \mathrm{a}_{2}=8.38018, \mathrm{a}_{3}=-4.00601, \mathrm{a}_{4}=0.32861,
$$

$$
a_{5}=-27.78753, a_{6}=0.22034, a_{7}=-1.50483 \text { and } a_{8}=-4.17818
$$

Therefore, defining characteristics of WECS, first the cost of each kWh of electricity consumed by family is substituted by CPU. This cost is calculated for each family by dividing total consumed power price on the bill by quantity of consumed units. Then, using this value as CPU, the hub height and rotor diameter can be determined using (18) in relation to each other. Placing value of $\mathrm{CPU}$ in this equation, gives us some reasonable values for the both parameters regarding standard range of these parameter values for small wind turbines. Having these values and referring to mentioned equations, other technical information of a specific WECS and also its investment cost, for each pair of the parameter values, will be easily determined. This relation is very suitable and valuable because of preparing necessary data for establishment of a WECS for each consumer. Besides, this is usable for other applications of wind turbines and can help consumers, as an analytical tool, to be informed about appropriate details of WECS. Also, referring to the last column of table 3-6, difference between CPU of power generated using wind turbines and the cost of power generated by hydro power plants without subsidy (in minimum 750-800 Rials per $\mathrm{kWh}$ ) is too little. Of course, this can be reduced by increasing rotor diameter and hub height of wind turbine.

Due to elimination of transmission, distribution of electricity and maintenance costs, using small wind turbines in suburb of a city or in rural areas is economically efficient. Furthermore, if wind turbine is installed on the roof of tall buildings, cost of hub height and following the PVC of WECS can be decreased. Considering these facts, generating power using wind turbines is more feasible compared to non-renewable power plants and it can take the place of central power plants extension, even as distributed generation. 


\section{Consequence}

It is necessary to extend utilization of renewable energies due to mortality of fossil fuels and environmental pollution. A type of energy that can be used for power generation is wind energy. This paper that is developed in realm of utilization of small wind turbines to distributed generation power required in household/commercial and agricultural sectors, presents a decision-making process to technically define characteristics of WECS and other criteria affecting it. Generally, two factors affecting CPU are identified as turbine attributes and climate conditions of installation location. Analyzing total energy output of WECS and CPU of generated power, rotor diameter and hub height are clarified as the main parameters influencing CPU. Mathematical relation between CPU versus rotor diameter and hub height as an essential tool to apply the process, is derived according to the analysis performed for four locations having different geographical and climate conditions with correlation coefficient $\approx 1$. Using this relation by substituting CPU of power consumed by family and defining distinct values of both rotor diameter and hub height of turbine, all information of different WECS related to each pair of the values, will be accessible and ultimately suitable WECS will be chosen by consumer regarding economical and other criteria. Besides, this relation is usable for each WECS contented by large wind turbines. Furthermore, comparing the calculated CPU by the $\mathrm{CPU}$ of power generated using current power plants, it is clear that employing WECS is economically and logically feasible. This is highlighted when WECS is established for supplying power required for rural residential or suburb gardens, which costs of transmission and distribution are removed.

\section{REFERENCES}

[1] A, El-Mallah and A.M. Soltan. "A nomogram for estimating capacity factors of wind turbines using site and machine characteristics.” Solar Wind Technology, 6 (1989), 633-635.

[2] Achraf, Abdelkafi, Abdelkarim Masmoudi and Lotfi Krichen. "Experimental investigation on the performance of an autonomous wind energy conversion system". Electrical Power and Energy Systems, 44 (2013), 581-590.

[3] Ahmet Z., Sahin, and Ahmet Aksakal. "Wind power energy potential at the North-eastern region of Saudi Arabia." Journal of Renewable Energy, 14 (1998), 435-440.

[4] Ali, Naci Celik. "Energy output estimation for small-scale wind power generators using Weibull-representative wind data." Journal of Wind Engineering and Industrial Aerodynamics, 91 (2003), 693-707.

[5] American Wind Energy Association (AWEA), the US Small Wind Turbine Industry, Roadmap, a 20-Year Industry Plan for Small Wind Turbine Technology, 2002.

[6] Amir Hossein, Ghorashi, and Abdulrahim Rahimi.
"Renewable and non-renewable energy status in Iran: art of know-how and technology-gaps." Renewable Sustainable Energy, 15 (2011), 729-736.

[7] AS, Ahmed Shata, and Rolf Hanitsch. "Evaluation of wind energy potential and electricity generation on the coast of Mediterranean Sea in Egypt." Journal of Renewable Energy, 31 (2006), 1183-1202.

[8] AS, Ahmed Shata, and Rolf Hanitsch. "Electricity generation and wind potential assessment at Hurghada; Egypt." Renewable Energy, 33 (2008), 141-148.

[9] BK, Gupta. "Weibull parameters for annual and monthly wind speed distributions for five locations in India." Journal of Solar Energy, 37 (1986), 469-471.

[10] Ciprian, Vlad, Iulian Munteanu, Antoneta. Iuliana Bratcu and Emil Ceangă. "Output power maximization of low-power wind energy conversion systems revisited: Possible control solutions." Energy Conversion and Management, 51 (2010), 305-310.

[11] D, Poje, and B Cividini. "Assessment of wind energy potential in Croatia." Solar Energy, 41 (1988), 543-554.

[12] DA, Barber, A Court and EW Hewson. "Wind characteristics, Wind Energy Over the United States." Final Report; Wind Energy Mission Analysis, ERDA Contract AT (04-3)-1075, Lockheed-California Company; [chapter 3], 1977.

[13] Dawud, Fadai. "The feasibility of manufacturing wind turbines in Iran." Renewable Sustainable Energy, 11 (2007), $536-542$.

[14] Du, Wenjuan, HF Wang, S Cheng, JY Wen and R Dunn. "Robustness of damping control implemented by energy storage systems installed in power systems." International Journal of Electric Power Energy System, 33 (2011), 35-42.

[15] Fortis turbine prices, http://www.fortiswindenergy.com/eng/ prices.asp [Fortisprices of complete systems for utility (in $€)$ ].

[16] Global Wind Energy Council (GWEC), Global wind energy outlook, Amsterdam: Greenpeace International, 2010.

[17] GM, Joselin herbert, $\mathrm{S}$ Iniyan, $\mathrm{E}$ Sreevalsan and $\mathrm{S}$ Rajapandian. "A review of wind energy technologies." Renewable and Sustainable Energy Review, 11 (2007), $1117-1145$

[18] Gong, Li, and Jing Shi. "Applications of Bayesian methods in wind energy conversion systems." Renewable Energy, 43 (2012), 1-8

[19] HS, Bagiorgas, MN Assimakopoulos, D Theoharopoulos, D Matthopoulos and GK Mihalakakou. "Electricity generation using wind energy conversion systems in the area of Western Greece." International Journal of Energy Conversion and Management, 48 (2007), 1640-1655.

[20] International Energy Agency (IEA), World energy outlook, Paris: OECD/IEA, 2010.

[21] International Energy Agency (IEA), Renewable information, Paris: OECD/IEA, 2010.

[22] JK, Kaldellis. "Integrated electrification solution for autonomous electrical networks on the basis of RES and energy storage configurations." Energy Conversion Management, 49 (2008), 3708-3720. 
[23] Manfred, Lenzen, and Jesper Munksgaard. "Energy and CO2 life cycle analyses of wind turbines - review and applications.” Renewable Energy, 26 (2002), 339-362.

[24] MA, AL-Fawzan. "Methods for Estimating the Parameters of the Weibull Distribution." King Abdulaziz City for Science and Technology; Saudi Arabia, 2000.

[25] Murat, Gokcek, and Mustafa Serdar Genc. "Evaluation of electricity generation and energy cost of wind energy conversion systems (WECSs) in Central Turkey." Applied Energy, 86 (2009), 2731-2739.

[26] Nasser, Bagheri Moghaddam, Sayyed Moslem Mousavi, Masoud Nasiri, Enayat A. Moallemi and Hami Yousefdehi. "Wind energy status of Iran: Evaluating Iran's technological capability in manufacturing wind turbines." Renewable and Sustainable Energy Reviews, 15 (2011), 4200-4211.

[27] Proven turbine prices, http://www.provenenergy.com/ [Wind turbine characteristics and Proven price list (in GBP)].

[28] RC, Bansal, TS Bhatti and DP Kothari. "On some of the design aspects of wind energy conversion systems." Energy Conversion Management, 43 (2002), 2175-2187.

[29] Reinhard, Madlener, and Jochen Latz. "Economics of centralized and decentralized compressed air energy storage for enhanced grid integration of wind power." Applied Energy Journal, 101 (2013), 299-309.

[30] Renewable Energy Organization of Iran (SUNA), http://www.suna.org.ir/fa/ationoffice/windenergyoffice/wind atlasmap, 2010.

[31] REN21. Global status report, Available from: www.ren21.net [cited10.09.2009], 2007.

[32] RH, Crawford. "Life cycle energy and greenhouse emissions analysis of wind turbines and the effect of size on energy yield." Renewable and Sustainable Energy Reviews, 13 (2009), 2653-2660.

[33] S, Clarke. "Electricity Generation Using Small Wind Turbines at Your Home or Farm." Ministry of Agriculture Food and Rural Affairs, http://www.omafra.gov.on.ca/englis h/engineer/facts/03-047.htm, 2003.

[34] S, Olayinka Ohunakin, S Joshua Ojolo, S Babatunde Ogunsina and R Rufus Dinrifo. "Analysis of cost estimation and wind energy evaluation using wind energy conversion systems (WECS) for electricity generation in six selected high altitude locations in Nigeria." Energy Policy, 48 (2012), 594-600.

[35] S, Rehman, TO Halawnai and M Mohandes. "Wind power cost assessment at twenty locations in the Kingdom of Saudi Arabia." Renewable Energy, 28 (2003), 573-83.

[36] Seyit Ahmet, Akdag, and O"nder G"uler. "Evaluation of wind energy investment interest and electricity generation cost analysis for Turkey.” Applied Energy, 87 (2010), 2574-2580.

[37] Shafiqur, Rehman. "Prospects of wind farm development in Saudi Arabia.” Renewable Energy, 30 (2004), 447-463.

[38] Statistical Centre of Iran,http://www.amar.org.ir/Default.asp $\mathrm{x}$ ?tabid=260, 2010.

[39] Talon turbine prices,http://www.magnet4sale.com/Wind-Po wer/ [Talon wind turbine prices (in \$)].

[40] Turbine Prices, http://www.allsmallwindturbines.com/ [all prices of related turbines (in $€$ )].

[41] World Wind Energy Association (WWEA), World wind energy report 2009, Bonn: World Wind Energy Association, 2010 . 